\title{
Um estudo sobre atitudes linguísticas na comunidade virtual: xômano que mora logo ali
}

\author{
A study on linguistic attitudes in the virtual community: xômano que mora logo \\ ali
}

\author{
Rayani Andressa da Cruz Oliveira ${ }^{1}$ \\ Universidade do Estado de Mato Grosso \\ Jocineide Macedo Karim ${ }^{2}$ \\ Universidade do Estado de Mato Grosso
}

\begin{abstract}
- RESUMO: Este artigo tem por objetivo identificar e compreender atitudes linguísticas em relação ao falar cuiabano, representado no site facebook dentro da comunidade virtual do Xômano que mora logo ali. Verificamos, assim, o posicionamento dos integrantes diante desses usos linguísticos mais característicos do falar cuiabano, além de aspectos culturais, que marcam a linguagem. Assim, para este trabalho selecionamos como corpus quatro avaliações realizadas pelos integrantes da comunidade, além de dois depoimentos deixados na linha do tempo da página virtual que juntos as avaliações corroboraram para compreendermos as estratégias implícitas de acomodação com a linguagem, dos integrantes.
\end{abstract}

- PAlaVRaS-ChaVE: Sociolinguística. Atitudes linguísticas. Teoria da acomodação. comunidade virtual. Facebook.

- ABSTRACT: This article aims to identify and understand linguistic attitudes in relation to Cuiabano speaking, represented on the facebook site within the virtual community of Xômano who lives right there. Thus, we verify the positioning of the members in the face of these linguistic uses that are more characteristic of Cuiaban speaking, in addition to cultural aspects, which mark the language. Thus, for this work, we selected as corpus four evaluations carried out by members of the community, in addition to two statements left in the timeline of the virtual page that together the evaluations corroborated to understand the implicit strategies of accommodation with the language of the members.

- KEYWORDS: Sociolinguistics. Linguistic attitudes. Accommodation theory. virtual community. Facebook.

\footnotetext{
${ }^{1}$ Doutoranda do Programa de Pós-Graduação em Linguística - PPGL - Universidade do Estado de Mato Grosso, Cáceres, Mato Grosso, Brasil. E-mail: raycruzandressa@gmail.com

2 Professora do Programa de Pós-Graduação em Linguística - PPGL - Universidade do Estado de Mato Grosso, Cáceres, Mato Grosso, Brasil. E-mail: jocineidekarim@yahoo.com.br
} 


\section{Considerações iniciais}

Em tempos de conectividade percebemos o quanto a interatividade das pessoas na internet, a partir das redes sociais, principalmente a mais popular ofacebook, expandese cada vez mais. Pois, é uma nova forma de comunicação da qual possui funcionalidades que chamam à atenção, como por exemplo, as comunidades virtuais ou fanpages as quais possibilitam que passemos a compreender a dinamicidade e heterogeneidade da língua, isso porque ela se exibe de diferentes formas, de acordo com a situação comunicativa em que se encontra.

Os indivíduos, ao fazerem parte de uma comunidade virtual, vão em busca de novas formas de interação e buscam espaços nos quais tenham algo em comum que desejam compartilhar e mantê-los ativos. Apesar de a comunicação online acontecer de inúmeras formas, é através da escrita que ela se desenvolve com características que a aproximam da oralidade. Esse recurso, tem por objetivo tornar a interação mais próxima de uma conversação face a face, faz com que os interagentes se sintam mais à vontade $\mathrm{e}$ aumente o fluxo de comunicação verbal.

Nessa direção, compreendemos a necessidade de desenvolver um estudo ${ }^{3}$ na área da linguagem sobre essas novas formas de interação. Para tanto, escolhemos a comunidade do Xômano que mora logo ali, que se constitui no espaço virtual da rede social facebook. A escolha de tal comunidade considerou o grande número de pessoas que a integram e que a aproximação das pessoas se dá por meio da existência de traços identitários comuns e pelo interesse em determinados assuntos como a linguagem e a cultura cuiabana.

Desse modo, este estudo surgiu a partir do interesse em observar como os indivíduos produzem e buscam informações que os representem e os identifiquem, de acordo com seu comportamento local no ambiente virtual. Encontramos uma comunidade em que acontece uma grande valorização das variantes estigmatizadas por meio da identificação cultural. Nesse sentido, indagamos: Por que os indivíduos buscam ambientes virtuais para utilizarem a variante cuiabana? E mais: como isso ocorre no ambiente virtual? Nossa hipótese é a de que as pessoas buscam por seus semelhantes, e os espaços virtuais têm correspondido a essas buscas, por meio de publicações que representam a cultura e o falar cuiabano.

Para a consecução da pesquisa, contamos com o aporte teórico da Sociolinguística e suas vertentes como a Sociologia da Linguagem e a Teoria da Acomodação. Assim teremos embasamento para a compreensão de questões relacionadas à variação linguística que estão assentadas em determinadas atitudes linguísticas manifestadas pelos integrantes da comunidade virtual.

\section{Atitudes linguísticas e Teoria da Acomodação}

Sabemos que a linguagem possui diversas características e que são, frequentemente, centro de 'opiniões' quase sempre permeadas por situações contraditórias, mas que podem dizer muito sobre a diversidade linguística, bem como sobre o predomínio de uma determinada variedade sobre a outra. Assim, levando em conta essa realidade, alguns estudiosos têm desenvolvido pesquisas no âmbito da Sociolinguística, procurando entender e descrever a variação, para além do que é dado linguisticamente. As pesquisas realizadas por Labov (1982 [1966] e 1972) são exemplos

\footnotetext{
${ }^{3}$ Este artigo é uma parte adaptada de minha dissertação de mestrado, intitulada: Variação Linguística e Identidade nas Redes Sociais: O falar cuiabano do Xômano que mora logo ali, desenvolvida sob a orientação da Profa. Dra. Jocineide Macedo Karim.
} 
de estudos realizados, os quais mostram que, para entender a variação linguística, é necessário ir além do que se observa nos dados de fala e investigar as relações estabelecidas entre os informantes e a sociedade em que estes se encontram.

Desse modo, o que notamos no espaço off-line, foi que em algumas situações, as variantes encontradas nos dados de fala são distintas daquelas que frequentemente são denominadas como corretas e aceitas por uma parcela da sociedade, a ocorrência dessas variantes menos prestigiadas está relacionada a uma preocupação em ser aceito socialmente. Todavia, observamos que nos espaços online, como na comunidade do xômano que mora logo ali está ocorrendo um processo de manutenção das variantes do falar cuiabano tidas como estigmatizadas nos espaços off-line. Em casos como esses, os pressupostos da Teoria da Acomodação podem lançar luz sobre os dados e ajudar a entender o comportamento linguístico desses integrantes da comunidade virtual.

Pois, a Teoria da Acomodação, formulada no âmbito da Psicologia Social desde Giles, Taylor e Bourhis (1973), busca determinar como os falantes se acomodam linguisticamente ao interlocutor. Nesse sentido, temos uma questão que norteará esse estudo, levando em consideração a mobilidade atual em que as pessoas interagem concomitantemente nos espaços off-line e virtual: Por que os indivíduos estão buscando ambientes virtuais para utilizarem a variante cuiabana? Nossa hipótese é que as pessoas buscam por seus semelhantes, e os espaços virtuais têm proporcionado ambientes de identificação.

Assim, compreendemos que a Teoria da Acomodação junto à Sociolinguística dará suporte para respondermos a tal indagação. Visto que, o principal postulado da Teoria da Acomodação que nos interessa é o de que os indivíduos são motivados a ajustarem a sua fala ou acomodarem-se, a fim de expressarem valores, atitudes e intenções em relação a outras.

A Teoria da Acomodação comunicativa foi desenvolvida por Giles et al (1977), com o intuito de investigar as estratégias utilizadas na interação entre falantes (grupos e intergrupos) para alcançar a distância social desejada. Tornou-se mais interdisciplinar, permitindo então uma análise dinâmica em contextos variados para observar como os falantes vão se convergindo ou divergindo aos padrões comunicativos, acreditados como sendo característicos de seus interlocutores, observando a empatia e o desejo de sinalizar essa empatia, identidades sociais comuns, explicar a aprovação do outro, o respeito, a confiança, a cooperação e ainda desenvolver uma relação de proximidade ou difusão potencialmente flexível na situação comunicativa.

Desse modo, de acordo com Bortoni-Ricardo (2011, p. 106-107), faz necessário compreender que o modelo da acomodação é seguido de quatro teorias psicológicas direcionadas, respectivamente, para os princípios de atração-similaridade- apoio; atribuição causal e distinção entre grupo. Esse modelo criou três conceitos essenciais: convergência, divergência e complementariedade.

Em termos gerais, de acordo com o princípio de atração-similaridade-apoio, quanto mais parecidas forem as crenças, as atitudes e o comportamento de uma pessoa em relação às outras é mais provável que ela seja atraída por eles. Assim, a convergência da fala é um auxílio utilizado nessa busca pela atração e apoio. O termo convergência é estabelecido para referir-se ao processo de mudança de fala, pois assim os falantes se esforçam para se tornarem mais parecidos com aqueles que estão interagindo.

O processo oposto à convergência está à divergência linguística, um afastamento das características da fala dos interlocutores. É uma tática de dissociação social, utilizada por grupos étnicos como recursos para manutenção de sua identidade. Isto é um meio para ressaltar a similaridade dentro do grupo e a distinção fora do grupo. 
De acordo com Bortni-Ricardo (2011), devemos compreender que Giles e Powesland (1975) buscaram postular que o engajamento em um processo de convergência poderia resultar em um retorno social positivo, representado pelo aumento de aprovação.

Outro conceito importante para compreensão do fenômeno da Acomodação está relacionado à origem na Teoria da Atribuição Causal. Assim, qualquer pessoa tende a compreender e avaliar as ações dos outros em situações e intenções que ele entenda como causas do comportamento alheio.

O terceiro conceito criado pela Teoria da Acomodação é o da complementaridade de fala. Segundo Bortoni-Ricardo (2011, p. 109), “em uma interação didática, a relação é considerada completa quando se reconhece que um participante mantém um papel subordinado ao outro".

Desse modo, consideramos importante a tradição da Psicologia Social no que tange a sua preocupação com os fenômenos linguísticos, da qual nasceu o modelo da acomodação, pois representa colaboração relevante para um entendimento mais claro das causas e motivações da variação linguística.

\section{Atitudes linguística dos integrantes da comunidade do Xômano que mora logo ali}

Constatamos, inicialmente, que os internautas cuiabanos, usuários do site da rede social facebook, têm participado da disseminação de algumas páginas que apresentam conteúdos que valorizam a cultura regional, alcançando muitos fãs que ainda residem em Cuiabá, que não residem mais, mas possuem parentes ou contatos na cidade, a página do Xômano que mora logo ali, vai além das fronteiras cuiabanas, mobilizando leitores em todo o Brasil.

O falar cuiabano representado na comunidade virtual do Xômano, é o ponto em comum dos integrantes. Eles disfrutam de um ambiente diversificado e rico no que diz respeito à comunicação livre, acessível e espontânea, onde podemos visualizar a representação da riqueza linguística do falar da baixada cuiabana. Pois, estudos linguísticos, têm demonstrado como Cuiabá está perdendo seus traços linguísticos mais típicos. A comunidade virtual em questão busca manter esse falar.

Observamos nessa comunidade o uso de variantes que identificam a norma local da região cuiabana, algumas aparentemente exclusivas da região sudoeste do Estado de Mato Grosso e outras partilhadas com outras regiões do Brasil.

Assim, levando em conta os aspectos fonético e lexical, apresentamos três usos linguísticos característicos do falar local, claramente identificados e exemplificados a partir de trabalhos já realizados sobre a região, que podem ser visualizados nos posts publicados na comunidade virtual.

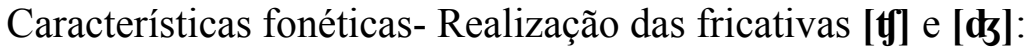

Post (01): Acordei pra esperar tchove pra dormir de novo...

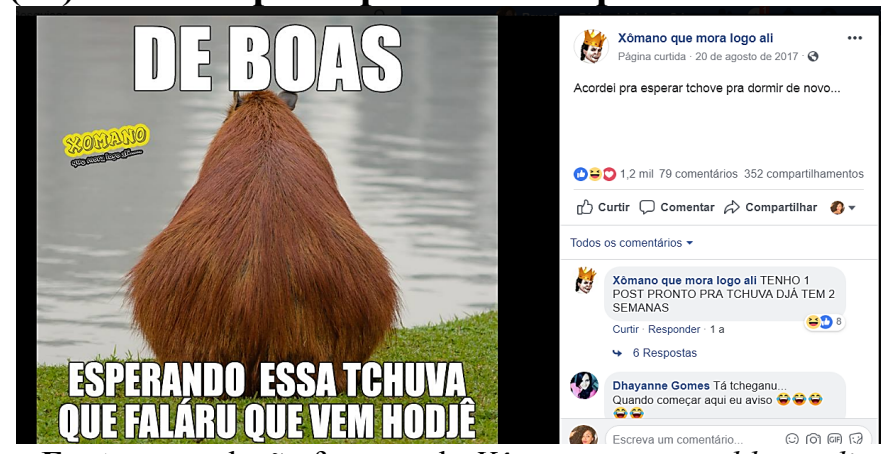

Fonte: reprodução fanpage do Xômano que moral logo ali 
As consoantes [t] e [dł], de acordo com Silva Neto (1960), estão presentes em mais de uma fase da história da língua portuguesa e permanecem vivas até hoje na expressão oral de muitos cuiabanos. O que se pode observar diante dos estudos sobre o falar cuiabano, é que dentre os aspectos fonológicos a realização das fricativas palatais [J] e [3] como as africadas [t $\mathbf{f}]$ e [d] $]$, tem sido vista como grande característica do falar cuiabano e, não incomum.

Outra característica fonética marcante, do falar cuiabano é a realização do rotacismo da lateral alveolar em grupo consonantal e em coda silábica:

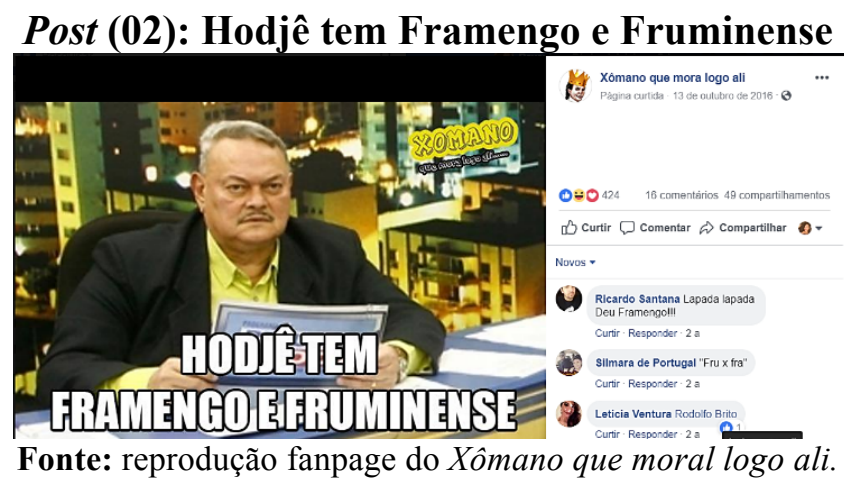

Entre os fenômenos fonológicos presentes no falar cuiabano podemos encontrar também o rotacismo. Desse modo, cabe ser aqui apresentado como um traço característico do falar cuiabano pela sua intensidade. Então, ouve-se, por exemplo [r] em vez de [I], [framengo] e [frruminense] no lugar de [flamengo] e [fluminense]. Sabemos que esse traço é um fenômeno estigmatizado, pela sua ligação com a ruralidade, oralidade e analfabetismo, sendo assim é um marcador social.

Contudo, na região Cuiabana, é um indicador linguístico, pois reúne, indistintamente, falantes das zonas rural e urbana, com diferentes níveis de escolaridade, e ocorre em contextos de interação mais ou menos formais.

As características lexicais, também são traços marcantes do falar cuiabano. Destacamos a seguir, um item lexical usual na comunidade virtual analisada e aparentemente exclusivo do sudoeste do Mato Grosso.

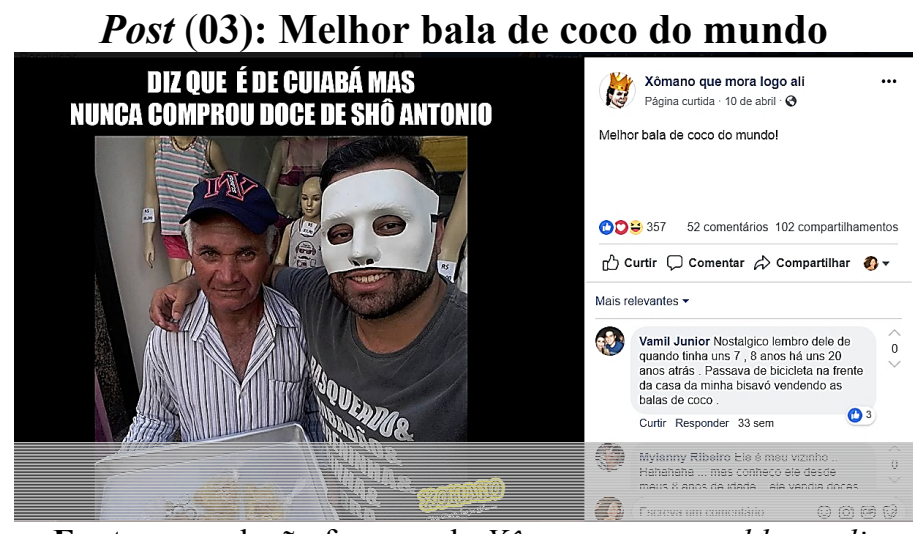

Fonte: reprodução fanpage do Xômano que moral logo ali.

Na comunidade do Xômano que mora logo ali, o uso das formas shô são constatadas, com o valor de senhor/seu. Macedo-Karim (2012) em um estudo sobre A comunidade são Lourenço em CáceresMT: Aspectos linguísticos e culturais atestou outra 
forma grafada como, xônei com o mesmo valor de senhor/seu, na região de Cáceres, em nome de estabelecimento comercial localizado no centro da cidade.

Desse modo, a interação na comunidade virtual acontece dos posts que representam o falar cuiabano. E, também por meio de uma das funcionalidades mais importantes que o facebook oferece para as comunidades virtuais, é o recurso de Classificação e Avaliação por parte dos integrantes. A Classificação é representada por notas de 1 a 5, demonstrada através de estrelas azuis; a Avaliação é um comentário complementar que o usuário pode fazer ou não. Com base no comentário/opinião de 380 pessoas (conforme especifica a página), e, de acordo com os mecanismos de explicação da página, compreende-se que a classificação é baseada em quantas pessoas recomendam ou não a página.

A sociedade em rede, inserida no espaço virtual tem propriedade globalizante e permite aos seus usuários a inserção e o acesso a qualquer grupo (comunidade virtual) social ou cultural. Assim, compreendemos a identidade e o sentimento de pertença que a comunidade do Xômano que mora logo ali produz para os integrantes, faz com que eles interajam dentro e fora da comunidade.

Nesse contexto, a partir das avaliações sobre a comunidade, deixadas pelos integrantes, tomamos como concepção de análise as noções relacionadas com os gostos, humor e linguagem, de modo que percebemos ser possível afirmar que a página virtual Xômano que mora logo ali, é a representação da cultura e do falar cuiabano. E desse modo, sugerir que os integrantes dessa comunidade estão verdadeiramente interligados e interagem virtualmente pelo vínculo linguístico e sociocultural que os ligam, e, consequentemente, os identificam.

Ao estudar as crenças e atitudes dessa comunidade, percebemos que, algumas vezes, elas se correspondem quando expressam opinião, gosto, preferência e também perante as escolhas que são feitas em determinada situação. E devemos acrescentar, ainda, que as atitudes linguísticas são definidas por julgamentos favoráveis ou desfavoráveis sobre a variedade linguística utilizada por determinadas pessoas.

Nesse sentido, observamos que as avaliações deixadas na página pelos integrantes podem ser percebidas como atitudes. Assim, Lambert e Lambert (1966, p. 77) destacam que "uma atitude é uma maneira organizada e coerente de pensar, sentir e reagir em relação a pessoas, grupos, questões sociais ou, mais genericamente, a qualquer acontecimento ocorrido em nosso meio circundante".

As análises aqui realizadas, tomam como referência o fato que a língua é um dos traços culturais adquiridos em virtude de um indivíduo integrar um determinado grupo social ou comunidade linguística.

Para tanto, selecionamos avaliações publicadas pelos integrantes da comunidade virtual do Xômano que mora logo ali, as quais revelam o posicionamento do falante com relação à identidade linguística em contexto multicultural. Seguem as avaliações (01) e (02) nas quais podemos classificar as avaliações como positivas:

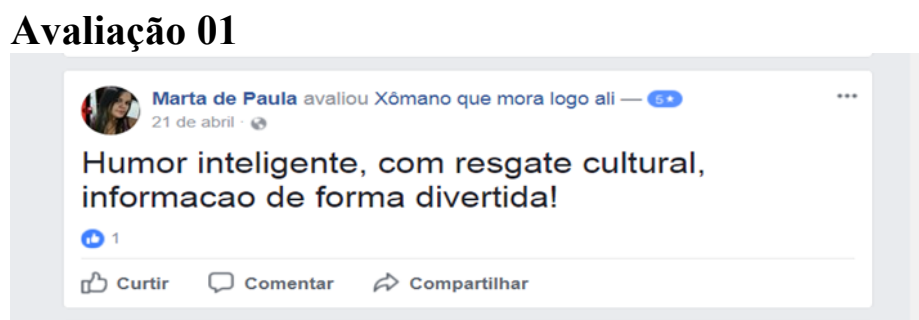

Fonte: reprodução fanpage do Xômano que mora logo ali. 


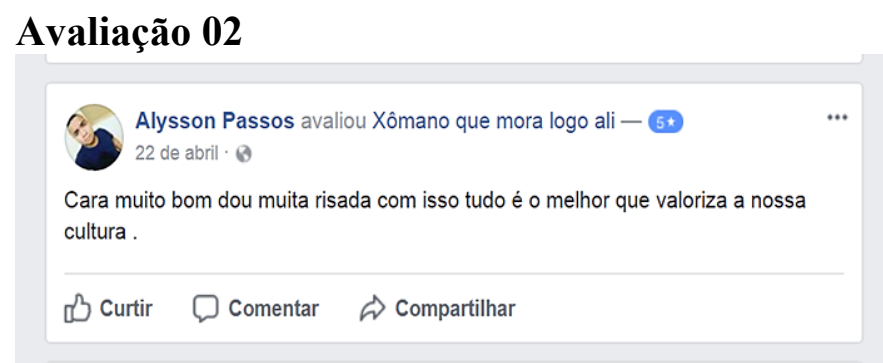

Fonte: reprodução fanpage do Xômano que mora logo ali.

Desse modo, gostaríamos de destacar primeiro as afirmações das avaliações (01) e (02): "humor inteligente/dou muita risada" isso porque o riso, sendo algo constante na vida e na história do ser humano, tem provocado o interesse de muitos pesquisadores na área da linguagem.

Segundo Possenti (1998), no que se refere à Linguística, o humor quase não tem sido alvo de pesquisa como realmente deveria, uma vez que os textos de humor são um excelente objeto de análise para o estudioso da língua. Eles dispõem de uma grande riqueza de elementos e informações que contribuem para um estudo completo do funcionamento e da estrutura da linguagem (verbal).

Contudo, nos estudos da linguagem, o humor nem sempre é bem visto, pois conforme o autor Luiz Carlos Travaglia, pensando no modo como o humor se constitui, podemos visualizar que o humor é algo que vai além da propensão de causar o riso:

\footnotetext{
O humor é uma atividade ou faculdade humana cuja importância se deduz de sua enorme presença e disseminação em todas as áreas da vida humana, com funções que ultrapassam o simples fazer rir. Ele é uma espécie de arma de denúncia, de instrumento de manutenção do equilíbrio social e psicológico; uma forma de revelar e de flagrar outras possibilidades de visão do mundo e das realidades naturais ou culturais que nos cercam e, assim, de desmontar falsos equilíbrios. (TRAVAGLIA, 1990, p.55).
}

O fato de situações humorísticas nas redes digitais serem promovidas por meio da representação da fala de alguém desencadeia nos integrantes atitudes de risos diante de determinados falares. O humor engloba todos os outros aspectos das publicações da comunidade virtual, sendo ele a característica essencial no sentido de causar empatia, entendendo o humor como uma forma de crítica compreensiva pautada num sentimentalismo que, ao mesmo tempo valoriza e aprofunda o real. Desse modo, como visto acima os integrantes da comunidade avaliam as publicações da comunidade a partir do humor e para analisar essas avaliações e publicações, abordamos a ideia do que se conhece como "humor cuiabano".

De acordo com Tylor (1871), o termo cultura é compreendido como um conjunto complexo incluindo os saberes, as crenças, a arte, os modos, o direito, os costumes, assim como toda disposição ou uso aprendido pelo homem vivendo em sociedade. Por conseguinte, por ser um atributo distintivo, a cultura acaba tornando-se fator determinante de identidade. No entanto, a construção de identidade pode acontecer de diversas formas, principalmente através da linguagem. Isso por ser a língua parte social da linguagem e a linguagem manifestação do comportamento social.

Nesse sentido, percebemos que a comunidade virtual do Xômano que mora logo ali, além de operar na disseminação da cultura cuiabana, desperta nos integrantes a percepção da sua identidade linguística, uma vez que é a partir da manifestação cultural em circunstâncias coletivas, que nos auto identificamos.

Segundo Dubar (1991): 


\begin{abstract}
A identidade humana não é obtida de uma vez por todas no nascimento: ela se constrói na infância e, doravante, deve se reconstruir ao longo da vida. O indivíduo nunca a constrói sozinho; ela depende dos julgamentos dos outros quanto suas orientações e das definições de si. [...] A identidade é ao mesmo tempo estável e provisória, individual e coletiva, subjetiva e objetiva, biográfica e estrutural, dos diversos processos de socialização que constroem os indivíduos se definem as instituições. (DUBAR, 1991, p. 07).
\end{abstract}

Assim, através do humor as publicações contribuem para a popularidade dos aspectos linguísticos da nossa região, como a fomentação da identificação cultural dos cuiabanos, para o seu senso de pertença a essa cultura e de que modo esse "retorno às origens" pode ser possível na era digital. Com efeito, então, essas comunidades virtuais 'regionalistas' mostram a cultura e a identidade cuiabana, fazendo uso do humor para representar situações que remetem ao cotidiano e à memória coletiva regional. Levam os integrantes da comunidade a valorizar mais região por meio dos elementos da cultura cuiabana identificados na página, sejam expressões típicas e características de Cuiabá, sejam os costumes e situações do cotidiano retratadas pelas publicações do Xômano que mora logo ali.

Apesar de serem retratados de forma cômica, acreditamos que a página acaba por contribuir de forma positiva para a disseminação da cultura cuiabana e para o fortalecimento da linguagem e da identidade desses cuiabanos que participam dessa comunidade virtual. É justamente esse fator da diversidade linguística que nos interessa nesta página do facebook.

Assim, seguidamente notamos que grande parte dos integrantes apresentam atitudes positivas ao descrever o conteúdo da comunidade, manifestaram em suas avaliações sentimento de orgulho pela terra cuiabana, uma vez que ele identifica o povo daquela região, a origem é enfatizada nas avaliações dos dois integrantes abaixo:

\title{
Avaliação 03

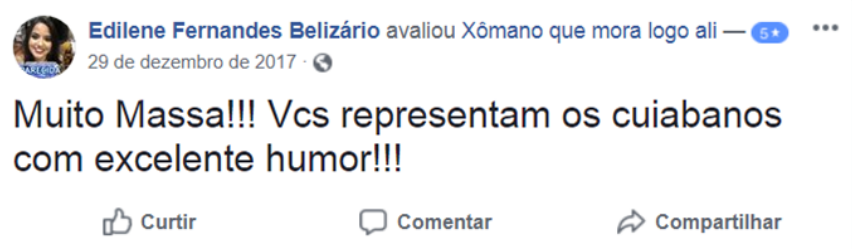

Fonte: reprodução fanpage do Xômano que mora logo ali.

Acreditamos que a comunidade virtual do Xômano que mora logo ali vem influenciando positivamente nas atitudes dos integrantes. As crenças e as atitudes linguísticas que emergem, motivam os integrantes da comunidade a adotarem determinadas posturas que favorecem um e outro grupo, no caso, aqueles que nem mesmo conhecem pessoalmente a região cuiabana,

Como identificado das avaliações dos integrantes da comunidade, acreditamos que essas atitudes positivas em relação à comunidade do Xômano que mora logo ali se dão porque há uma relação de identidade com o falar, com os aspectos culturais representados na página.

Sobre essa relação, recorremos a Amâncio (2007) que explica:

Desse modo, a partir da observação das atitudes manifestadas por um grupo em relação à fala do outro, faz-se possível analisar se há ou não uma relação de identidade - linguística e social - entre eles. Inversamente, a identidade expressa ou não por um grupo em relação a outro pode também influenciar as atitudes manifestadas. (AMÂNCIO, 2007, p. 51). 
Desse modo, o que observamos é que uma característica definidora da identidade do grupo ou indivíduo é a variedade linguística assumida e, assim, qualquer atitude em relação aos grupos com determinada identidade pode ser uma resposta às variedades usadas por esse grupo ou aos indivíduos usuários dessa variedade.

A seguir, destacamos a avaliação (04), o parecer de uma integrante da comunidade, em que podemos perceber que o indivíduo, ao se inserir em uma comunidade virtual, busca traços de identificação.

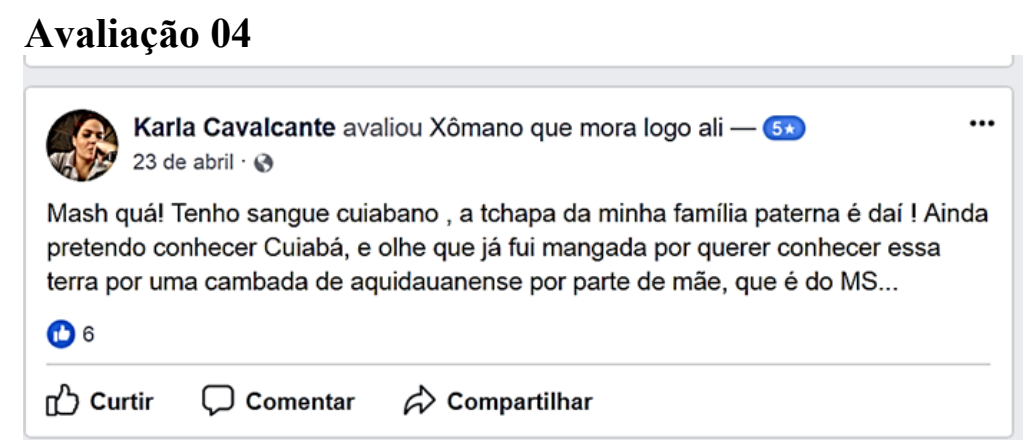

Fonte: reprodução fanpage do Xômano que mora logo ali.

Percebemos, na avaliação acima, que a integrante utiliza algumas expressões linguísticas cuiabanas; quá - que significa expressão de espanto, indignação. Ex: 'Quá! Pode esquecer ele não volta mais." e tchapa- uma expressão linguística utilizada pelos Cuiabanos, aos que nascem em Cuiabá. Os descendentes dos fundadores da cidade receberam posteriormente o carinhoso tratamento de "cuiabano de tchapa e cruz".

Assim, podemos compreender a afirmação de Tarallo $(2011$, p.14) de que a língua pode ser um fator extremamente importante na identificação de grupos e no modo de indicar diferenças sociais presentes nessa comunidade. A integrante da comunidade, mesmo não conhecendo a cidade, possui traços linguísticos adquiridos pelos pais e emprega expressões linguísticas utilizadas na comunidade como fator identificação.

Os integrantes da comunidade virtual, buscam valorizar os traços linguísticos do falar cuiabano, eles reconhecem o estigma e preconceito para com a variedade linguística cuiabana. Como demonstra a avaliação (04): "e olhe já fui mangada por querer conhecer essa terra por uma cambada de aquidauanense por parte de mãe, que é do $M S$...."

Verificamos, a força da comunidade virtual do Xômano que mora logo ali, em combater o preconceito linguístico, pois conforme Bagno (2001, p.115-117), reagir ao preconceito requer uma mudança de atitude, do usuário da língua materna, elevando o grau da própria autoestima linguística. Desse modo, percebemos, pela avaliação da integrante da fan page a comunidade virtual é um espaço onde o usuário, além de se identificar linguisticamente, proporciona a formação da identidade do indivíduo, pois as identidades parecem invocar uma origem, residiria em um passado histórico com o qual estas identidades continuariam a manter certa correspondência. As identidades têm a ver, entretanto, com a questão da utilização dos recursos da história, da linguagem e da cultura

4 Encontramos definições sobre as expressões; quá e tchapa em uma matéria intitulada "Liguadjá Cuiabanês" escrita por Ivana Schäfer. 
para a produção não daquilo que nós somos, mas daquilo no qual nos tornamos (HALL, 2000, 109).

Desse modo, podemos ver como os integrantes, sentem orgulho e apreço pelo falar cuiabano representado na comunidade virtual do Xômano que mora logo ali. A representatividade do falar cuiabano, acontece na comunidade virtual de modo único e original. E, isso transcende os limites geográficos, uma vez que pessoas de outras regiões participam e se identificam com a comunidade.

\section{A comunidade Xômano como representação de identidade pessoal}

Seguindo com a nossa análise, gostaríamos de demonstrar a importância da identidade pessoal do indivíduo. Isso porque, ela é construída no campo social, no qual os indivíduos buscam integração por meio da língua, e assim se "moldam" ao grupo que estão ou desejam estar inseridos.

Assim, relacionando as atitudes linguísticas dos integrantes da comunidade virtual ao aspecto social, podemos retomar os quatro princípios de Le page (1980), demonstra a identidade e a linguagem estão intimamente ligadas:

\footnotetext{
1. A capacidade do falante de identificar o grupo modelo ou grupo referência;

2. A capacidade ter acesso a esses grupos e a habilidade de trabalhar as regras de seu repertório;

3. O peso de motivações conflitantes (motivações em relação a um outro grupo modelo em relação à preservação de sua própria identidade);

4. A habilidade de modificar seu comportamento linguístico. (LE PAGE, 1980, p. 31).
}

A partir dessas condições que caracterizam o comportamento linguístico de um indivíduo, é possível notar, as escolhas linguísticas estão conectadas à identidade social do falante. Assim, podemos compreender, o integrante da comunidade virtual do Xômano que mora logo ali possui habilidade ao utilizar seu repertorio linguístico conforme o falar da comunidade virtual, através de suas semelhanças linguísticas, pois a comunidade do xômano é o grupo modelo para os integrantes.

No modelo de La pege (1980, p. 20), "o que estrutura a identidade em todas as suas dimensões é linguagem, e "o outro" do discurso não é representado pelo interlocutor a quem se dirige e sim ao grupo de referência". Consciente ou não, o integrante da comunidade virtual não se dirige ao um interlocutor face a face, mas sim a comunidade a qual ele escolheu fazer parte. Encontramos a explicação para esse sentimento de pertencimento do integrante da comunidade do Xômano que mora logo ali, no fenômeno da Acomodação, pois a teoria firma que os indivíduos são motivados a ajustarem a sua fala ou acomodarem.

Nesse sentido, quando encontramos uma comunidade na qual existe uma grande valorização de variantes estigmatizadas, por meio da identificação cultural, indagamos: Por que os indivíduos estão buscando ambientes virtuais para utilizarem a variante cuiabana? Como isso está ocorrendo nesse ambiente virtual? Nossa hipótese é que as pessoas buscam por seus semelhantes, por sua identidade linguística e cultura, e os espaços virtuais têm correspondido a essas buscas por meio de publicações que representam a cultura e o falar cuiabano proporcionando "segurança na comunidade".

Constatamos que a comunidade do Xômano que mora logo ali, a partir do facebook, enquanto suporte das relações sociais, vem modificando os processos sociais das pessoas, possibilitando aos usuários a investir virtualmente nesses laços sociais de interação com a variedade linguística cuiabana. 
Como sabemos, no mundo offline existe um conflito de orientação para o prestigio e para a identidade linguística e cultural, como podemos ver no depoimento (01) que segue abaixo:

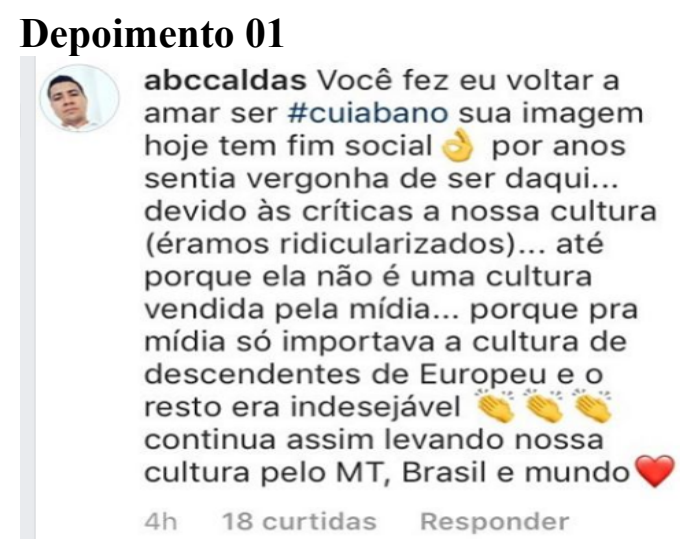

Fonte: reprodução fanpage do Xômano que mora logo ali.

No depoimento (01), vimos um conflito com a orientação de prestigio. Quando o integrante afirma que: "Por anos senti vergonha de ser daqui...", percebemos que o sentimento de vergonha em relação a sua regionalidade esteja em processo de mobilidade social ascendente, no qual tendem a adotar valores de um grupo de referência, o indivíduo tende a acomodar seu repertório linguístico, seus costumes ao grupo que deseja pertencer, como Labov (1972/2008) afirmou. Assim, compreendemos que o integrante do depoimento (01) assume uma identidade imposta por instituições.

Todavia, no espaço virtual, por meio da comunidade do Xômano que mora logo $a l i$, o integrante encontra um grupo, o qual deseja fazer parte e não entra em conflito com sua identidade pessoal, pois a comunidade valoriza o falar e a cultura cuiabana, leva ao indivíduo sentimento de pertencimento ao grupo. Podemos notar quando ele afirma: "vocêfez eu voltar a amar ser cuiabano... sua imagem hoje tem fim social".

O sentimento de pertença é aquele que ajuda o integrante a identificar "de onde ele é". E o grupo de pessoas com o mesmo sentimento de pertença faz com que exista uma identidade coletiva, ela será a mesma entre os que partilham desse mesmo sentimento. E esse sentimento se expressa na comunidade virtual, através de depoimentos como esse acima e toda a interação com as publicações da comunidade.

Desse modo, o sentimento de pertença dos integrantes para com a comunidade, tem relação direta com a identidade de um povo, por aflorar devido o reconhecimento coletivo racional e emocional dos símbolos e valores da cultura cuiabana.

Assim, compreendemos, vivemos inseridos em redes sociais. Ligamo-nos às pessoas por meio de uma rede invisível e maleável, a qual nos conecta a nossos círculos sociais, profissionais, familiares possibilitando várias trocas de experiências em nossas atividades no dia a dia. Na interação diária, cada falante utiliza uma ou outra variedade linguística, depende do papel social, representado em cada uma de suas diversas situações de interação, mas também entram no jogo interativo, sendo determinantes na opção por qual variedade fazer uso nesses momentos.

No ambiente virtual não é diferente, pois ao fazerem parte de uma comunidade virtual como a do Xômano que mora logo ali, os integrantes da comunidade, mesmo inconscientemente, buscam estar conectados com pessoas que possuem atitudes e crenças semelhantes à deles, no caso o ponto em comum é a variedade linguística cuiabana. 
Desse modo, partimos da compreensão sobre a comunidade virtual do Xômano que mora logo ali centra-se em integrantes sociais, isto é, indivíduos com interesses, desejos e aspirações, as quais têm papel ativo na formação de suas conexões sociais.

A comunicação mediada por computador, os indivíduos compartilham não apenas informações, mas também, suporte emocional e companheirismo.

Gostaríamos de demonstrar com esses resultados, são as variantes consideradas estigmatizadas. As quais, encontram-se majoritariamente nos espaços off-line, como demonstra o estudo realizado por Cox (2005). Diferentemente ocorre na comunidade virtual, pois, como constatamos, a variação acontece de forma natural e humorística. $\mathrm{O}$ comportamento positivo dos integrantes pode ser medido de forma positiva em relação às variantes, de acordo com a repercussão dos posts e as avaliações deixadas pelos integrantes da comunidade virtual.

Desse modo, a confirmação da hipótese para nosso questionamento começa aqui, visto que dentro dos ambientes virtuais os falantes talvez possuam a variedade cuiabana no processo de acomodação, uma vez que eles desejam interagir conforme as variantes aceitas pelo grupo, no caso aquelas consideradas, até então, fora desse grupo como estigmatizadas.

Assim, se nós retomarmos as publicações feitas na comunidade virtual, veremos elas funcionando como instrumento para o integrante da comunidade interagir com o falar cuiabano. Os resultados sobre a avaliação dos integrantes, mostram que eles estão relacionados à questão de identidade como fator de divergência, ou seja, resistência em utilizar a norma padrão de prestigio dentro da comunidade virtual. Isso porque a resistência em acomodar o próprio falar a uma norma se dá principalmente pelo orgulho que se tem de sua comunidade dialetal.

Seguem algumas das expressões deixadas pelos integrantes que demonstramos na subseção anterior como nas avaliações (01) "resgate cultural" e avaliação (02) "valoriza nossa cultura" e outros depoimentos nos quais, também podemos visualizar o orgulho dos integrantes em participar de uma comunidade virtual, a qual representa sua comunidade de origem, como nos depoimentos (01) e (02) segue abaixo:

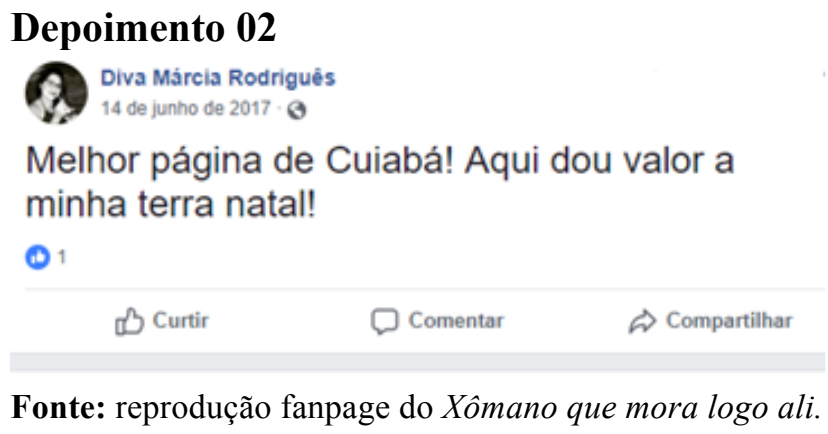

Aqui destacamos a frase: "Aqui dou valor a minha terra natal" 


\section{Depoimento 03}

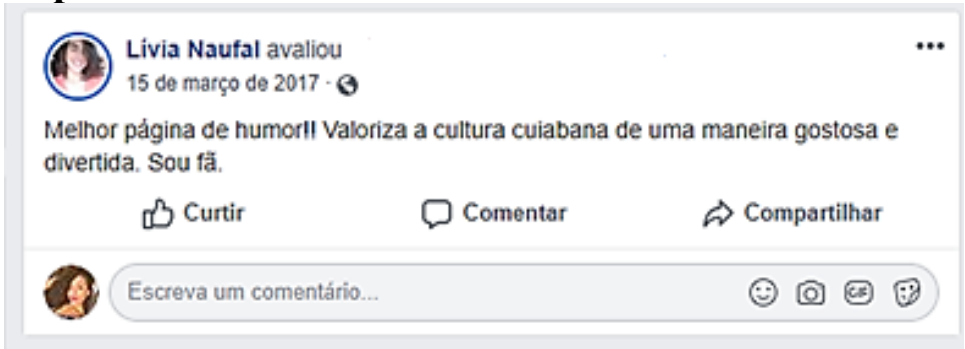

Fonte: reprodução fanpage do Xômano que mora logo ali.

E o depoimento (02) "valoriza nossa cultura". Observa-se, independente da região, a qual possam residir atualmente todos parecem sentir orgulho de sua comunidade de origem. As raízes geográficas estão diretamente relacionadas às experiências que são constitutivas da identidade.

A estratégia da divergência, nesse caso, pode aproximar os integrantes na interação, pois o integrante deseja estar em conformidade com o grupo. Assim, quando está em jogo o prestígio do dialeto, eles tendem a entrar em um processo de convergência, por isso implica um retorno social positivo daquele grupo. Então, ao interagirem na comunidade com a variedade da maioria estão no processo de atração e apoio. Assim, o grande número de participantes na comunidade, os semelhantes se aproximam, buscam essa aproximação.

Todas as vezes que os integrantes expressam sua preocupação em preservar o sotaque e com isso a identidade por meio do sotaque que é representado nas publicações, possivelmente estarão a atuar pela estratégia da divergência, resistindo à mudança, a comunidade em geral tende a manutenção do falar cuiabano.

Conforme nossas reflexões, a avaliação dos integrantes e a diversidade da fala estão ligadas, conceitualmente, aos estudos linguísticos e aos estudos da Psicologia Social. Segundo Giles, Taylor e Bourthis (1973), o desejo pela aprovação social, está no centro da Teoria da Acomodação. Já Giles e Powesland (1975) reafirmam essa assertiva ao concluir que a acomodação é o resultado de uma tentativa do falante em se esforçar para ser aceito pelo interlocutor.

Por meio da análise dos dados, foi possível observar, tanto através das avaliações dos integrantes quanto através das interatividades nas publicações, e ao contrário do que estudos já feitos sobre a Teoria da Acomodação apontam, os integrantes se afastam da variedade tida como prestigio nos espaços face a face e aproximam-se das pronúncias, as quais julgam prestigiosas dentro da comunidade virtual. Aquelas, vistas como variantes mais estigmatizadas do falar cuiabano. Assim, verifica-se, existe a intenção, por parte dos integrantes, de serem aceitos socialmente dentro da comunidade que é estigmatizada fora do espaço virtual e faz parte de seus idioletos.

Desse modo, como mostram os estudos realizados no campo da Teoria da Acomodação, nas situações propícias à acomodação da fala, os falantes recorreram às variantes linguísticas que julgam prestigiosas, dentre aquelas que lhes são possíveis representar. Essa ação é entendida pela teoria como um reflexo do desejo do indivíduo de aprovação social.

\section{Considerações gerais}

Assim, foi possível identificar as atitudes dos integrantes da comunidade analisada, revelaram sentimentos positivos perante o uso das variantes mais características de Cuiabá. Para os integrantes, interagir na comunidade do Xômano é 
interagir com traços já esquecidos pelos cuiabanos, é resgatar a cultura local e mais que isso, é manter vivo o falar cuiabano, visto que fora do ambiente virtual eles não possuem esse contato com esse falar. Diante do exposto, percebe-se que a interação dos integrantes com as publicações na página e as avaliações deixadas por eles demonstram atitudes positivas frente ao falar cuiabano, representando na comunidade virtual os usos linguísticos regionais mais característicos de Cuiabá.

Identificamos que o falar cuiabano, representado na comunidade, é uma característica definidora da identidade do grupo ou indivíduo. A variedade linguística é assumida e, assim, qualquer atitude em relação aos grupos com determinada identidade pode ser uma resposta às variedades usadas por esse grupo ou aos indivíduos usuários dessa variedade. Ainda que não estejam expressas nas avaliações dos integrantes da comunidade, o fator linguagem, sabemos como as normas e marcas culturais dos falantes se transmitem ou se sedimentam por meio da língua, atualizada na fala de cada indivíduo.

\section{REFERÊNCIAS}

AMÂNCIO, R. G. As cidades trigêmeas: um estudo sobre atitudes linguístico-social e identidade. Dissertação (Mestrado em Estudos da Linguagem). Campinas: UNICAMP, 2007. 102 f. Universidade Estadual de Campinas, Campinas, 2007. Disponível em: http://repositorio.unicamp.br/jspui/handle/REPOSIP/268962. Acesso em: 01 out. 2018.

BAGNO, Marcos. Preconceito Linguístico - o que é, como se faz. São Paulo: Edições Loyola, 2001.

BORTONI-RICARDO, S. M. Do campo para a cidade: estudo sociolinguístico de migração e redes sociais. São Paulo: Parábola, 2011.

COX, M. I. P. \& Santiago-Almeida, M. M. (orgs.). Vozes cuiabanas: estudos linguísticos em Mato Grosso. Cuiabá: Cathedral, 2005, p.183-212.

DUBAR, C. La socialisation. Construction dês indentités sociales ET professionnelles. Paris: Armand Colin, 1991.

GILES, H.; TAYLOR, D.; BOURHIS, R. Toward a theory of interpersonal accommodation through speech: some Canadian data. Language in Society, v. 2. Cambridge: Cambridge University Press, p. 177-192, 1973.

GILES, H.; POWESLAND, P. F. Speech style and social evaluation. London: Academic press Inc., 1975

FACEBOOK. Xômano que mora logo ali. Disponível em: https://web.facebook.com/XomanoQueMoraLogoAli. Acesso em: 05 de janeiro de 2019

HALL, Stuart. Quem precisa da identidade? In. Identidade e diferença: a perspectiva dos estudos culturais / Tomaz Tadeu da Silva (org). Petrópolis - RJ: Vozes, 2000.

LABOV, William. (1972). O quadro social da mudança linguística. IN: Padrões sociolinguísticos. Tradução de Marcos Bagno, Maria Marta Pereira Scherre, Caroline R. Cardoso. São Paulo, SP: Parábola, 2008. p. 301-373. 169.

LAMBERT, William W.; LAMBERT, Wallace E. Psicologia Social. Rio de Janeiro: Zahar editors, 1966.

LE PAGE, R. B. Projection, Forcusing and Diffusio. York Papers in Lingustics, 1980.

POSSENTI, Sírio. Os humores da língua: análises linguísticas de piadas. Campinas, SP Mercado de Letras, p.152, 1998. 
MACEDO-KARIM, Jocineide. A comunidade São Lourenço em Cáceres-MT: aspectos linguísticos e culturais. Tese de Doutorado. Universidade Estadual de Campinas. Campinas, SP, 2012.

SANTIAGO-ALMEIDA, Manoel M.. . 2000. 319 f. Tese (Doutorado) - Curso de Faculdade de Filosofia, Letras e Ciências Humanas, Letras Clássicas e Vernáculas, Usp/fflch, São Paulo, 2000.

TARALLO, Fernando. A pesquisa sociolinguística. $8^{\mathrm{a}}$ ed. São Paulo: Ática, 2007.

TRAVAGLIA, L. C. Uma introdução ao estudo do humor pela linguística. DELTA, v. 6, n. 1, p. 55-82, 1990.

TYLOR, Edward. B. Primitive Culture: Researches into the Development of Mythology, Philosophy, Religion, Language, Art, and Custom. $6^{\text {a }}$ ed. 2 vols. London: John Murray, 1920 [1871].

Recebido em: junho de 2020. Aprovado em: agosto de 2020.

\section{Como citar este trabalho:}

OLIVEIRA, R. A. da C.; KARIM, J. M. Um estudo sobre atitudes linguísticas na comunidade virtual: xômano que mora logo ali. Traços de Linguagem, v. 4, n. 1, p. 89-103, 2020. 